\title{
3 Research Square

\section{Emission sources, Characteristics and risk assessment of particulate bound Polycyclic Aromatic Hydrocarbons (PAHs) from traffic sites}

Balram Ambade ( $\square$ bambade.chem@nitjsr.ac.in )

National Institute of Technology (NIT) Jamshedpur-831014

Amit Kumar

National Institute of Technology (NIT) Jamshedpur-831014

Mohd Latif

Malaysia Department of Environment

\section{Research Article}

Keywords: PM2.5, PAHs, Health Risk, Diagnostic Ratio, NAAQs, Backward trajectories

Posted Date: March 30th, 2021

DOI: https://doi.org/10.21203/rs.3.rs-328364/v1

License: (c) (i) This work is licensed under a Creative Commons Attribution 4.0 International License.

Read Full License 


\section{Abstract}

Atmospheric PM2.5 size particulate-associated Polycyclic Aromatic Hydrocarbons (PAHs) were analyzed from December 2018 to May 2019 over three traffic sites of Chota Nagpur Plateau (CNP) of India were analyzed to study their temporal and seasonal variations. Over the last few decades, CNP becomes a hotspot of air pollution due to traffic and anthropogenic activities. The PM2.5 concentration was higher than the value given by the National Ambient Air Quality (NAAQ) standard value. The results show the total average concentration of PAHs was found 141.48 $\pm 22.86,163.80 \pm 30.43$, and $171.60 \pm 26.23 \mathrm{ng} / \mathrm{m} 3$ over site (Adityapur) ADP, (Sakchi) SKI, and Mango (MGO), respectively. The PM2.5 total average concentration was found $67.91 \pm 14.04,79.70 \pm 13.53$, and $103.20 \pm 21.77 \mu \mathrm{g} / \mathrm{m} 3$ over site ADP, SKI, and MGO, respectively. Diagnostic ratio analysis reveals that the source of PM2.5 associated with PAHs was petrogenic, pyrogenic, coal combustion, and vehicular emission. Backward trajectories model and fire count data were also used for air parcel movement up to height $4500 \mathrm{~m}$ above the earth's surface. The traffic campaign has provided a rare opportunity for the CNP region for the collection of more air pollution baseline data, which could be helpful in the formulation of air pollution reduction policies in the future

\section{Introduction}

Last few decades, air pollution becomes a major problem on the global platform. Particulate matter size less than $2.5 \mu \mathrm{m}\left(\mathrm{PM}_{2.5}\right)$ linked Polycyclic Aromatic Hydrocarbons (PAHs) becomes an excessive danger to human health as a consequence of its teratogenic, mutagenic, and carcinogenic properties (Kumar et al., 2020a). Due to the smaller particulate size, it cannot be trapped by the upper part of the respiratory tract and can penetrate the lungs (Thomas, 2013). Particulate having great adsorbing ability by providing a large surface area, where various toxic substances can deposit, including PAHs (Jermann et al., 1989). PAHs are persistent carbon-based combinations poised of two or additional aromatic rings fused (Yang et al., 2010; International Agency for Research on Cancer (IARC), 1984, 1983; Boeuf et al., 2016; Kumar et al., 2020a). Based on molecular weight, PAHs categories into two classes, Low molecular weight PAHs including two-three rings fused, exist in the vaporous stage, and high molecular weight PAHs, including over four aromatic rings, occur in the particulate stage (Chrysikou and Samara 2009; Baek et al., 1991). United States of Environmental Protection Agency (USEPA) recorded sixteen PAHs as significance pollutant and among them 7 PAHs including chrysene (Chry),benzo[b]fluoranthene (B[b]F), benzo[a]anthracene $(B[a] A)$, indeno[1, 2,3-c,d]pyrene (I[cd]P), benzo[a]pyrene $(B[a] P)$, dibenz $[a, h]$ anthracene $(D[a h] A)$, and benzo[k] fluoranthene $(B[k] F)$ have been categorized as feasible triggering of B2 course human carcinogens (USEPA., 2006).

In emerging countries like India, It is essential to identify air pollution due to traffic emissions. High highway traffic flow is one of the most significant homes of particulate-associated PAHs emission (Yin et al., 2010). The particulate bound PAHs in traffic emission source including, diesel and gasoline exhaust, fuel evaporation, brake pads wear and disc brake, spillage of fuel and lube oil, drains and road outward materials, re-suspension of highway dust, separating, abridgment (Lawrence et al., 2013; Boonyatumanond et al., 2007). Previous studies reported that the motor vehicle contributing $46-90 \%$ of 
particulate-bound PAH emissions in the urban atmosphere (Jang et al., 2013). Apart from these coals, wood, and biomass burning, industrial emission, like anthropogenic activities, are also responsible for particulate-bound PAHs in the traffic zone (Zhang et al., 2008). Long-distance transport is also accountable for particulate-bound PAHs in the traffic zone (Ravindra et al., 2008). Anthropogenic activities are responsible for particulate emission. Biological activities, including forest fire and volcanic eruption, are also accountable for particulate-bound PAHs in the atmosphere (Kumar et al., 2020a; Xu et al., 2006; Baek et al., 1991).

Jamshedpur is an economic megacity in the Chota Nagpur Plateau (CNP) region provoked by heavy air effluence (Kumar et al., 2020b). The present study, identify of PAH were conducted from December 2018 to May 2019. The samples were collected by mini volume sampler to assess PM2.5 bound PAH concentrations temporal deviations and understand probable source ranges of PAH using diagnostic ratio (DR) models. Furthermore, we also consider the spatial and periodic features of PM2.5 associated PAHs. These study potential implications will be to make a more robust air quality management plan of the city and recognize source-specific effects of particulate matter on human health. The key objective was to expand better empathetic compound characteristics, seasonal disparity, probable causes, and human health hazard calculation due to particulate bound PAHs at Jamshedpur city traffic area.

\section{Materials And Methods}

\subsection{Study area}

Measurements of PM2.5 bound PAHs have been performed over three sites Adityapur (ADP), Mango (MGO), and Sakchi (SKI). The site selection was made in such a way that to cover the overall scenario and the small-vehicle, significant vehicle movement during the study area (Figure 1). The traffic site is located in Jamshedpur city, the central region of CNP India longitude and latitude $\left(22^{\circ} 80^{\prime} \mathrm{N}\right.$ and $86^{\circ} 20^{\prime}$ E). This town is bordered by luxurious green Dalma peaks covering $209 \mathrm{~km}^{2}$ at the Chota Nagpur Plateau (CNP). There are tropical dry and wet weather and climate over this study area. Conferring to the registration of 2011, Jamshedpur whole habitat is about 1.3 million, with 6400 persons per $\mathrm{km}^{2}$ density of populace (Census 2011). Total 833,983 registered vehicles are running in Jamshedpur, East Singhbhum district of Jharkhand state of India (https://vahan.parivahan.gov.in). Jamshedpur is one of the decent organized and biggest industrial Cities of CNP. More than one thousand industries are running under the Adityapur Industrial Development Authority (AIDA). Due to many industries such as chemical plants, paint industry, steel industry, plastic industry, etc., emission of large amounts of air pollutants. The transportation of goods and industrial products to other states leads to a high load on Jamshedpur traffic. Traffic emission is also responsible for the PAHs emission in the environment.

\subsection{Sampling procedure}

The ambient $\mathrm{PM}_{2.5}$ sample monitoring was performed from selected locations in CNP on the seasonal event. A total of 48 samples were collected throughout the winter and summer from December 2018- May 
2019. The sampling was done by a mini volume sampler (Envirotech Model type APM 550) functioning at a flow rate of $16.5 \mathrm{~L} / \mathrm{m}^{3}$. During the campaign $47 \mathrm{~mm}$ PTFE filter (Merck, Catalog no- PM2547050) was used to accumulate particulate-phase PAHs. Pre-digested filters were weighed thrice to get accurate weight before sampling. Loaded filter with particulate matter are also weighed thrice after sampling to decide the exact mass of the particulate by a lone pan-top packing numerical weight machine (VWR, Model no: VWR1611-2263: with Weighing chamber $\mathrm{L} \times \mathrm{W} \times \mathrm{H}: 162 \times 171 \times 225 \mathrm{~mm})$. Background impurity was checked by expending functioning blanks (unexposed filters) treated concurrently with field samples. Furthermore, the filter is kept in aluminum foil and packed well, and preserved in a culture box. Before the investigation, these samples were retained in a fridge at under $4^{\circ} \mathrm{C}$ for conservation.

\subsection{Sample analysis}

Analysis of filter containing $\mathrm{PM}_{2.5}$ associated 16 USEPA Priority PAHs including Napthelene (NAP), Acenaphthylene (Acy), Chrysene (Chr), Benzo[a]pyrene (BaP), Acenaphthene (Ace), Phenanthrene (Phe), Anthracene (Ant), Benzo[ghi]perylene (B(ghi)P), Fluoranthene (Flua), Pyrene (Pyr), Indeno[123-cd]pyrene (IcP) Fluorene, (Flu), Benzo[a]anthracene (BaA), Benzo[k]fluoranthene (BkF), Benzo[b]fluoranthene (BbF), and Dibenzo[ah]anthracene (DBahA), was performed. The filter paper was cut into smaller pieces. The filter was extracted with $200 \mathrm{ml}$ dichloromethane (DCM) for 20 hours with an identified extent of a standard surrogate solution of Pyrene-D10 (CAS Number -1718-52-1), Anthracene-D10 (CAS Number -1719-06-8), Phenanthrene-D10 (CAS Number -1517-22-2), Naphthalene-D8 (CAS Number -1146-65-2) and Chrysene-D12 (CAS Number -1719-03-5). After that, the extracted solution volume was reduced by the rotatory evaporator. The extracts were purified using sodium sulfate - silica gel column (glass column of $30 \mathrm{~cm}$ long and $3 \mathrm{~cm}$ diameter). The target solutions were eluted with $10 \mathrm{ml}$ dichloromethane (DCM) and hexane solvent $(1: 1 \mathrm{v} / \mathrm{v})$. The further purified excerpt was reduced up to $1-2 \mathrm{ml}$ by again rotatory evaporator. The PAHs were recognized by the Gas Chromatography attached by the Flame lonization Detector (GC- FID, Agilent-7890B) furnished with capillary pillar HP- 5MS $(30 \mathrm{~m} \times 0.32 \mathrm{~mm} \times 0.25 \mu \mathrm{m})$ with a seven-inch cage. In a split less manner, $1 \mu$ l of every sample was inserted. Nitrogen gas was used as a transferor gas with a flow rate of $2 \mathrm{ml} \mathrm{min}^{-1}$. The oven temperature was initiated at $60^{0} \mathrm{C}$ for $3 \mathrm{~min}$ and improved up to $320^{\circ} \mathrm{C}$ at the rate of $5^{0} \mathrm{C} \mathrm{min}^{-1}$ and hold for $20 \mathrm{~min}$. The peak area of individual bands and retention factor, the 16 USEPA significance PAHs concentrations were quantified. Recoveries of PAH complexes were above $75 \%$. The laboratory field test and blanks blank test has performed for samples were revealed and examined in the identical technique as field test sample investigation, and the PAH compound was not perceived in blank samples. The sample and blank solutions were then transferred into $50 \mathrm{~mL}$ vials, labeled, and stored in the refrigerator before analysis.

\subsection{Quality control}

The deuterated labeled PAHs; Pyrene-D10, Anthracene-D10, Phenanthrene-D10, Naphthalene-D8, and Chrysene-D12 were used for the recovery studies, and the recoveries were $98 \pm 13 \%, 82 \pm 14 \%, 92 \pm 13 \%$, $38 \pm 12 \%$, and $103 \pm 12 \%$, respectively. The method detection limits (MDLs) were examined using the laboratory blanks and 8 field blanks spiked with the known number of targeted PAHs standards. The 
MDLs were calculated as the mean concentration of target compounds in field blanks in addition to the blanks standard deviance three times. The limit of quantifications (LOQs) was designed as ten times the standard deviation. Field blank analysis was used to eliminate the error during the sampling campaign. The LOD and LOQ value was in the array of $0.01-0.05$ and $0.04-0.20 \mu \mathrm{g} / \mathrm{l}$ correspondingly. The concentration was less than the detection limit considered as $(<D L)$.

\section{Results And Discussion}

\subsection{Spatial-temporal variations of $\mathrm{PM}_{5}$ associated PAHs}

The detail of the seasonal concentration of PAHs and $\mathrm{PM}_{2.5}$ given in Table 1. The total average concentration of PAHs was found $141.48 \pm 22.86,163.80 \pm 30.43$, and $171.60 \pm 26.23 \mathrm{ng} / \mathrm{m}^{3}$ over site ADP, $S K I$, and MGO, respectively. The $\mathrm{PM}_{2.5}$ total average concentration was found $67.91 \pm 14.04,79.70 \pm 13.53$, and $103.20 \pm 21.77 \mu \mathrm{g} / \mathrm{m}^{3}$ over site ADP, SKI, and MGO, respectively. The concentration of $\mathrm{PM}_{2.5}$ was more significant than the national ambient air quality (NAAQ) standards value of $40 \mu \mathrm{g} / \mathrm{m}^{3}$ (NAAQS, .2009) over the three study sites.

The $\mathrm{PM}_{2.5}$ associated with PAH concentration was recorded higher in the winter season than the summer season over the study site ADP, SKI, and MGO. The PAHs concentration in the winter season was found $160.40 \pm 13.34,190.70 \pm 16.58$, and $194.77 \pm 12.30 \mathrm{ng} / \mathrm{m}^{3}$ over area $\mathrm{ADP}, \mathrm{SKI}$, and MGO, respectively. PAHs concentration during the summer season was $122.56 \pm 11.13,136.90 \pm 7.36$, and $148.44 \pm 9.81 \mathrm{ng} / \mathrm{m}^{3}$ at ADP, SKI MGO, respectively. The total average concentration of $\mathrm{PM}_{2.5}$ was found $80.27 \pm 6.62,90.80 \pm 8.46$, and $121.95 \pm 8.20 \mu \mathrm{g} / \mathrm{m}^{3}$ in the winter season and summer season $55.55 \pm 5.44,68.61 \pm 6.28$ and $84.45 \pm 12.01 \mu \mathrm{g} / \mathrm{m}^{3}$ over ADP, SKI, and MGO site, respectively. The seasonal concentrations of $16 \mathrm{PAHs}$ are plotted in Figure 2, and the total average concentrations of PAHs and $\mathrm{PM}_{2.5}$ are shown in Figure 3.

Calculated $\mathrm{PM}_{2.5}$ linked PAHs in the winter season was found more remarkable than other seasons because of the primary source of emission, such as domestic cooking or heating emission, vehicular emission, etc. Additionally, the concentration was high because of the reduction of atmospheric dispersion of particulate and PAHs concentration sorption on particulate bound PAHs due to a decrease in air temperature (Ravindra et al., 2008). Furthermore, particulate-bound PAH concentration is generally found less in the warm period because of less emission from primary sources. Metrological conditions like higher temperature and wind allow them to dispersion with higher mixing height, favoring the pollutant in gas phase portioning and photodegradation of $\mathrm{PM}_{2.5}$ associated PAHs. A similar seasonal variation has been designated in earlier work (Chrysikou and Samara, 2009; Gianelle et al., 2013).

\subsection{Diagnostic Ratio Analysis}

Diagnostic ratios of PAHs were used to deliver reliable evidence on PAH's emission cause in the atmosphere. The ratio of Ant/(Ant+Phe), Flua/(Flua+Pyr), Flua/Pyr, Phen/Ant IcP/(IcP+B(ghi)P), and $\mathrm{BaP} / \mathrm{B}(\mathrm{ghi}) \mathrm{P}$ were used to determine the seasonal cause of emission of particulate linked PAHs. The 
value of Ant/(Ant+Phe) ratio is less than 0.1 directed petrogenic source and significance upper than the 0.1 indicated pyrogenic source over all the three traffic sites (Pies et al., 2008). The ratio of Flua/(Flua+Pyr) less than 0.1 directed petrogenic/ unburned petroleum source, the value found between $0.4-0.5$, the source is fossil fuel burning if value found higher than 0.5 the source identified as coal \& biomass burning (Yunker et al., 2002; De La Torre-Roche et al., 2009). The ratio of Flua/Pyr less than 0.1 directed, petrogenic cause, and larger than 1 indicated fossil fuel combustion cause (Sicre et al., 1987). The ratio of Phen/ Ant less than 10 indicated the pyrogenic source, and higher than 10 directed coal combustion was the predominant source. The ratio of $\mathrm{BaP} / \mathrm{B}(\mathrm{ghi}) \mathrm{P}$ and $\mathrm{IcP} /(\mathrm{Icp}+\mathrm{B}(\mathrm{ghi}) \mathrm{P})$ was an indicator for traffic and non -traffic emission sources of PAHs over all the site (Hussain et al. 2015). The PAHs ratio over three traffic sites ADP, SKI, and MGO, plotted in Figure 4, indicating the petrogenic, Pyrogenic, coal burning, and vehicular discharge was the chief source of emission of PAHs over the study site in both cold and warm seasons of CNP.

\subsection{Backward Trajectories}

The backward trajectories model was used for improved perception of contamination affected by air particulates transported by air or discharged by the resident basis causes. Proportions of height coordinates with respect 7- day isentropic back trajectory was investigated for full run time $168 \mathrm{~h}$ up to altitude level of $500 \mathrm{~m}$ with Meteorological Data Explorer (METEX, http://db.cger.nies.go.jp/metex/trajectory.html) in winter and summer season as shown in Figure 5. At various heights up to $4500 \mathrm{~m}$ beyond the ground, back trajectory analysis has been examined to elucidate aerosol possessions changeability linked with airborne particulate matter in the whole atmospheric outline on a seasonal basis. Winter season trajectories show that most of the Indo- Gangetic plain (IGP) mass is from the central Asia region. Summer season trajectories show that the aerosol mass loading form mainly originated from CNP. Some assembly was loaded from the Bengal region, south and south-Eastern part of the country.

Fire counts data were also incorporated in the backward trajectory model by the Moderate Resolution Imaging Spectroradiometer (MODIS) from the National Aeronautics and Space Administration (NASA) satellite was used to assess dynamic combustion over India during the study period. The unified fire count data are accessible at https://earthdata.nasa.gov/earth-observation-data/near-real-time/firms.

\subsection{Health Risk Assessment}

The adverse effect of the introduction of particulate-linked PAHs on human health is calculated by the equivalent toxicity concentration (TEQ) equation (Yu et al., 2008; Yang et al., 2007). TEQ expression represents the sum of assessed carcinogenic risk qualified to BaP for entirely PAHs having carcinogenic potential, which can be assessed by multiplying the concentration of every PAHs carcinogenic and toxicity equivalence factor (TEF) value given by Nisbet and Lagoy (1992) 1 value for BaP and DBahA, 0.1 value for $\mathrm{BaA}, \mathrm{BkF}$ and IcP, 0.01 value for Chr, Ant, and B(ghi)P and 0.01 for Phe, Flt, and Pyr for each $\mathrm{PAH}$. The following equation was used to determine the TEQ value. 
$\mathrm{TEQ}=\sum \mathrm{Ci} \times \mathrm{TEFi}$

Where $\mathrm{Ci}$ and TEFi represent the concentration of specific PAHs and toxic equivalency factors, respectively. DBahA and BaP contribute the highest carcinogenicity of $\mathrm{PAH}$ samples on average. BaP gives $35.72,38.11$, and $39.54 \%$ carcinogenicity over the PAHs samples traffic site, respectively. DBahA contributed 50.52, 47.82, and $45.25 \%$ carcinogenicity over ADP, SKI, and MGO sites, respectively. This confirms the surrogate compounds were DBahA and BaP in evaluating PAHs health threat.

The exposure threat due to individual PAHs can be quantitatively calculated by Incremental lifetime cancer risk (ILCR) (Peng et al., 2011; USEPA., 1991; Chen and Liao., 2006). ILCR was considered by assessing the corresponding lifetime average daily dose (LADD) of PAHs by allowing in two age group, children (age 6 years) and adult (age 70 years), having Inhalation rate (IR) air inhalation rate of 10 $\mathrm{m}^{3} /$ day for children and $20 \mathrm{~m}^{3} /$ day for an adult (Soltani et al., 2015). The Exposure frequencies (EF) were considered 365 days/year for both children and adults (Kumar et al., 2013). Bodyweight of child and adult were considered $18 \mathrm{~kg}$ for child and $60 \mathrm{~kg}$ for adults (ICMR., 2009), and the averaging time (AT) for hazards was 70 years. Exposure duration was considered as 24 years (USEPA., 2011). The following equation was used to calculate LADD and ILCR.

$\operatorname{LADD}\left(\mathrm{mg} \mathrm{kg}^{-1} \mathrm{day}^{-1}\right)=(\mathrm{Cs} \times \mathrm{IR} \times \mathrm{CF} \times \mathrm{EF} \times \mathrm{ED}) /(\mathrm{BW} \times \mathrm{AT})$

$\mathrm{ILCR}=\mathrm{LADD} \times \mathrm{CSF}$ (Cancer Oral Slope Factor)

Cs is the quantity of PAHs renewed concentration grounded on TEQ assessment in airborne particulate $\left(\mathrm{ng} / \mathrm{m}^{3}\right)$. In the present study, CSF symbolizes the inhalation cancer slope factor $\left(3.85 \mathrm{mg} \mathrm{kg}^{-1} \mathrm{day}^{-1}\right)$ (Peng et al., 2011). The LADD value and ILCR value were calculated, and the values of the details are presented in Table 3. Auxiliary, the Excess Life Time Cancer Risk (ELCR) was assessed by the sum of ILCR for Adult and ILCR value for the child overall study site. The ELCR value over ADP, SKI, and MGO sites was found $13.89 \times 10^{-6}, 16.17 \times 10^{-6}$, and $16.49 \times 10^{-6}$ respectively. The ELCR value lies in the tolerable limit 10 6-10-4 given by USEPA (USEPA. 1989). The outcome presented that the risk level was tolerable over ADP, SKI, and MGO traffic sites.

\subsection{Conclusion}

In the present study, $\mathrm{PM}_{2.5}$ associated PAHs were examined in three CNP traffic sites in the cold and warm seasons. The total average concentration of PAHs was found 141.48 $\pm 22.86,163.80 \pm 30.43$, and $171.60 \pm 26.23 \mathrm{ng} / \mathrm{m}^{3}$ over area ADP, SKI, and MGO, respectively. The $\mathrm{PM}_{2.5}$ total average concentration was found $67.91 \pm 14.04,79.70 \pm 13.53$, and $103.20 \pm 21.77 \mu \mathrm{g} / \mathrm{m}^{3}$ over site ADP, SKI, and MGO, respectively. The concentration of $\mathrm{PM}_{2.5}$ was found upper than the NAAQ standards value of $40 \mu \mathrm{g} / \mathrm{m}^{3}$ over the three study sites in together (cold and warm) season. The concentration of PM 2.5 linked PAHs was found upper in the cold season than the warm season. Diagnostic ratio analysis reveals that the source of $\mathrm{PM}_{2.5}$ allied PAHs was petrogenic, pyrogenic, coal combustion, and vehicular emission was the 
principal cause of emission of PAHs. Backward trajectories model and fire count data were also used for air parcel movement up to height $4500 \mathrm{~m}$ above the earth's surface. The health threat due to the introduction of $\mathrm{PM}_{2.5}$ linked PAHs was analyzed. $\mathrm{BaP}$ and DBahA were the highest contributors to carcinogenicity. BaP contributes $35.72,38.11$, and $39.54 \%$ carcinogenicity over the PAHs samples traffic site, respectively. DBahA contributed $50.52,47.82$, and $45.25 \%$ carcinogenicity over ADP, SKI, and MGO sites, respectively. LADD and ILCR value was also calculated for all the study site. The ELCR value over ADP, SKI, and MGO site was found $13.89 \times 10^{-6}, 16.17 \times 10^{-6}$, and $16.49 \times 10^{-6}$, respectively. The obtained data represent an exclusive contribution to the complex assessment of human exposure to PAHs in traffic sites, with the background of mid and heavy traffic zones.

\section{Declarations}

\section{Acknowledgments}

The present study was "financially helped by the Science \& Engineering Research Board, Department of Science \& Technology, (SERB- DST) Government of India. The author also thanks the Meteorological Data Explorer (METEX, http://db.cger.nies.go.jp/metex/trajectory.html) and NASA (National Aeronautics and Space Administration) fire information for resource and management system (FIRMS) for provision of trajectories data and fire count data (https://firms.modaps.eosdis.nasa.gov/download/) used in the publication".

\section{Compliance with Ethical Standards Conflict of interest}

The authors declare that they have no known competing financial interests or personal relationships that could have appeared to influence the work reported in this paper.

\section{References}

Baek, S.O., Goldstone, M.E., Kirk, P.W.W., Lester, J.N., Perry, R., 1991. Phase distribution and particle size dependency of polycyclic aromatic hydrocarbons in the urban atmosphere. Chemosphere. 22, 503-520.

Boeuf, B., Fritsch, O., and Martin- Ortega, J., 2016. Undetermining European environmental policy goals? The EU water framework directive and the politics of exceptions. Water: 388.

Boonyatumanond, R., Murakami, M., Wattayakorn, G., Togo, A., Takada, H., 2007. Sources of polycyclic aromatic hydrocarbons (PAHs) in street dust in a tropical Asian mega-city, Bangkok, Thailand. Sci. Total Environ. 384, 420- 432.

Chen, S.C. and Liao, C.M., 2006. Health risk assessment on human exposed to environmental polycyclic aromatic hydrocarbons pollution sources. Sci. Total Environ. 366, 112-123.

Chrysikou, LP., Samara, CA., 2009. Seasonal variation of the size distribution of urban particulate matter and associated organic pollutants in the ambient air. Atmos Environ. 43(30), 4557-4569. 
De La Torre-Roche, R.J., Lee, W.-Y., Campos-Díaz, S.I., 2009. Soil-borne polycyclic aromatic hydrocarbons in El Paso, Texas: analysis of a potential problem in the United States/ Mexico border region. J. Hazard. Mater. 163, 946-958.

Gianelle, V., Colombi, C., Caserini, S., Ozgen, S., Galante, S., Marongiu, A., Lanzani, G., 2013. Benzo(a)pyrene air concentrations and emission inventory in Lombardy region, Italy. Atmos Pollut Res. 4, 257-266.

Hussain, K., Rahman, M., Prakash, A., Hoque, R.R., 2015. Street dust bound PAHs, carbon and heavy metals in Guwahati city-Seasonality, toxicity and sources. Sustain Cities Soc. 19, 17-25.

IARC., 1984. Polynuclear aromatic compounds. Part 1. Chemical environmental and experimental and experimental data IARC Monographs on the Evaluation of the Carcinogenic Risk of Chemicals to Human, vol. 32. International Agency for Research on Cancer, Lyon, France. Indoor/outdoor PAH air pollution in Brazil. Environ. Pollut. 169, 210-216.

ICMR., 2009. Nutrient requirements and recommended dietary allowances for Indians. A report of the expert group of the Indian Council of Medical Research Hyderabad, India: National Institute of Nutrition.

International Agency for Research on Cancer (IARC) Benzo[a]pyrene, Polynuclear Aromatic Compounds, Part 1, Chemical, Environmental and Experimental Data, vol. 32, Monographs on the Evaluation of the Carcinogenic Risk of Chemicals to Humans, 1983, pp. 211-224.

Jang, E., Alam, M.S., Harrison, R.M., 2013. Source apportionment of polycyclic aromatic hydrocarbons in urban air using positive matrix factorization and spatial distribution analysis. Atmos. Environ. 79, 271285.

Jermann, E., Hajimiragha, H., Brockhaus, A., Freier, I., Ewers, U., Roscovanu, A., 1989 Exposure of children to benzene and other motor vehicle emissions. Zentralbl Hyg Umweltmed 189, 50-61.

Kumar, A., Ambade, B., Sankar, T.K., Sethi, S.S., Kurwadkar, S., 2020a. Source identification and health risk assessment of atmospheric $\mathrm{PM}_{2.5}$-bound polycyclic aromatic hydrocarbons in Jamshedpur, India.

Sustain. Cities Soc. 52, 101801.

Kumar, A., Sankar, T.K., Ambade, B., Sethi, S.S., 2020b. Characteristics, toxicity, source identification and seasonal variation of atmospheric polycyclic aromatic hydrocarbons over East India. Environ Sci Pollut Res. 27, 678-690

Kumar, M., Furumai, H., Kurisu, F., \& Kasuga, I., 2013. Tracing source and distribution of heavy metals in road dust: Soil and soak away sediment through speciation and isotopic fingerprinting. Geoderma. 211212, 8-17. 
Lawrence, S., Sokhi, R., Ravindra, K., Mao, H.J., Prain, H.D., Bull, I.D., 2013. Source apportionment of traffic emissions of particulate matter using tunnel measurements. Atmos. Environ. 77, 548-557.

NAAQS (National Ambient Air Quality Standards), 2009. Ministry of Forest and Environment. Government of India, New Delhi.

Nisbet, I.C.T., Lagoy, P.K., 1992. Toxic equivalency factors (TEFs) for polycyclic aromatic hydrocarbons (PAHs). Regul. Toxicol. Pharmacol. 16 (3), 290-300.

Peng, C., Chen, W.P., Liao, X.L., Wang, M.E., Ouyang, Z.Y., Jiao, W.T., Bai, Y., 2011. Polycyclic aromatic hydrocarbons in urban soils of Beijing: status, sources, distribution and potential risk. Environ. Pollut. 159, 802-808.

Pies, C., Hoffmann, B., Petrowsky, J., Yang, Y., Ternes, T.A., Hofmann, T., 2008. Characterization and source identification of polycyclic aromatic hydrocarbons (PAHs) in river bank soils. Chemosphere $72,1594-$ 1601.

Ravindra, K., Wauters, E., Van Grieken, R., 2008. Variation in particulate PAHs levels and their relation with the transboundary movement of the air masses. Sci Total Environ. 396, 100-110.

Soltani, N., Keshavarzi, B., Moore, F., Tavakol, T., Lahijanzadeh, A. R., Jaafarzadeh, N., \& Kermani, M., 2015. Ecological and human health hazards of heavy metals and polycyclic aromatic hydrocarbons (PAHs) in street dust of Isfahan metropolis, Iran. Sci. Total Environ. 505, 712-723.

Thomas, R.J., 2013. Particle size and pathogenicity in the respiratory tract. Landes Bioscience. 4:8, 847858.

U.S. EPA., 1991). Risk Assessment Guidance for Superfund, Volume 1, Human Health Evaluation Manual (Part B, Development of Risk-Based Preliminary Remediation Goals). OSWER; 1991 [9285.7-01B. EPA/540/R-92/003].

United States Environmental Protection Agency, 1989. Risk assessment guidance for superfund. vol. I. USEPA, Washington (Human health evaluation manual (part A). EPA 540-1-89-002, Office of Emergency and Remedial Response).

USEPA (2011). Exposure factors handbook edition. EPA/600/R-09/052F. Washington, D.C: National Center for Environmental Assessment, Office of Research and Development, U.S. Environmental Protection Agency 20460.

USEPA. 2006. Washington, DC: United States Environmental Protection Agency. United States Environmental Protection Agency. 2012. <http://www.epa.gov/reg3hwmd/risk/human>. Accessed 20 Dec 2012. 
Yang, F., Zhang, Q., Guo, H., \& Zhang, S. (2010). Evaluation of cytotoxicity, genotoxicity and teratogenicity of marine sediments from Qingdao coastal areas using in vitro fish cell assay, comet assay and zebrafish embryo test. Toxicology in Vitro, 24, 2003-2011.

Yang, X., Okada, Y., Tang, N., Matsunaga, S., Tamura, K., Lin, J., Kameda, T., Toriba, A. and Hayakawa, K. (2007). Long-Range transport of polycyclic aromatic hydrocarbons from China to Japan. Atmos. Environ. $41,2710-2718$.

Yin, J., Harrison, R.M., Chen, Q., Rutter, A., Schauer, J.J., 2010. Source apportionment of fine particles at urban background and rural sites in the UK atmosphere. Atmos. Environ. 44, 841-851.

Yu, Y., Guo, H., Liu, Y., Huang, K., Wang, Z. and Zhan, X., 2008. Mixed uncertainty analysis of polycyclic aromatic hydrocarbon inhalation and risk assessment in ambient air of Beijing. J. Environ. Sci. 20: 505512.

Yunker, M., MacDonald, R., Vingarzan, R., Mitchell, R., Goyette, D., Sylvestre, S., 2002. PAHs in the Fraser River basin: a critical appraisal of PAH ratios as indicators of PAH source and composition. Org. Geochem. 33, 489-515.

Zhang, H.R., Eddings, E.G., Sarofim, A.F., 2008. Pollutant emissions from gasoline combustion. 1. Dependence on fuel structural functionalities. Environ. Sci. Technol. 42, 5615-5621.

\section{Tables}

Due to technical limitations the Tables are available as a download in the Supplemental Files.

\section{Figures}

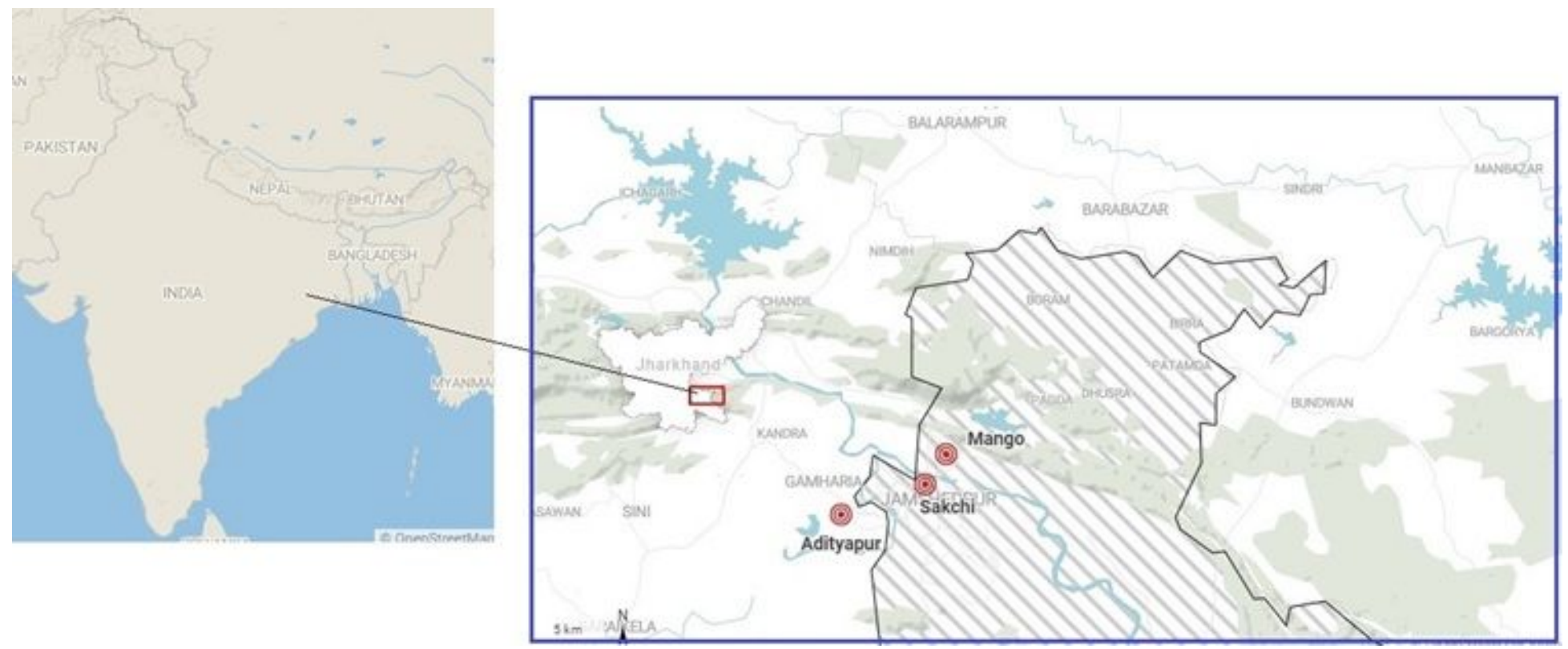




\section{Figure 1}

Three traffic sampling site of Adityapur (ADP), Sakchi (SKI), and Manno (MGO) area of East India. Note: The designations employed and the presentation of the material on this map do not imply the expression of any opinion whatsoever on the part of Research Square concerning the legal status of any country, territory, city or area or of its authorities, or concerning the delimitation of its frontiers or boundaries. This map has been provided by the authors.
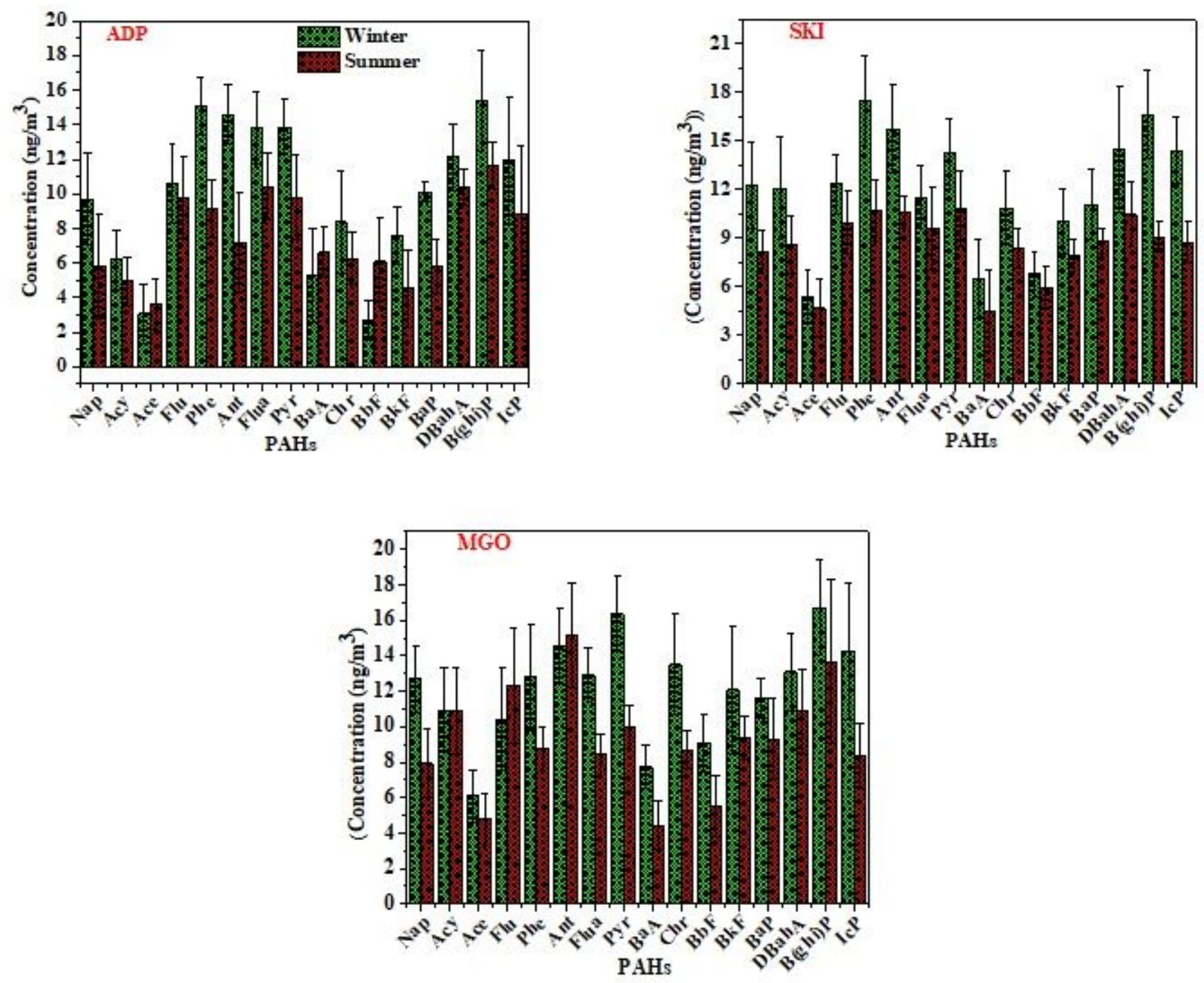

Figure 2

Concentration of PAHs in three traffic sites of Adityapur (ADP), Sakchi (SKI), and Manno (MGO) area. 

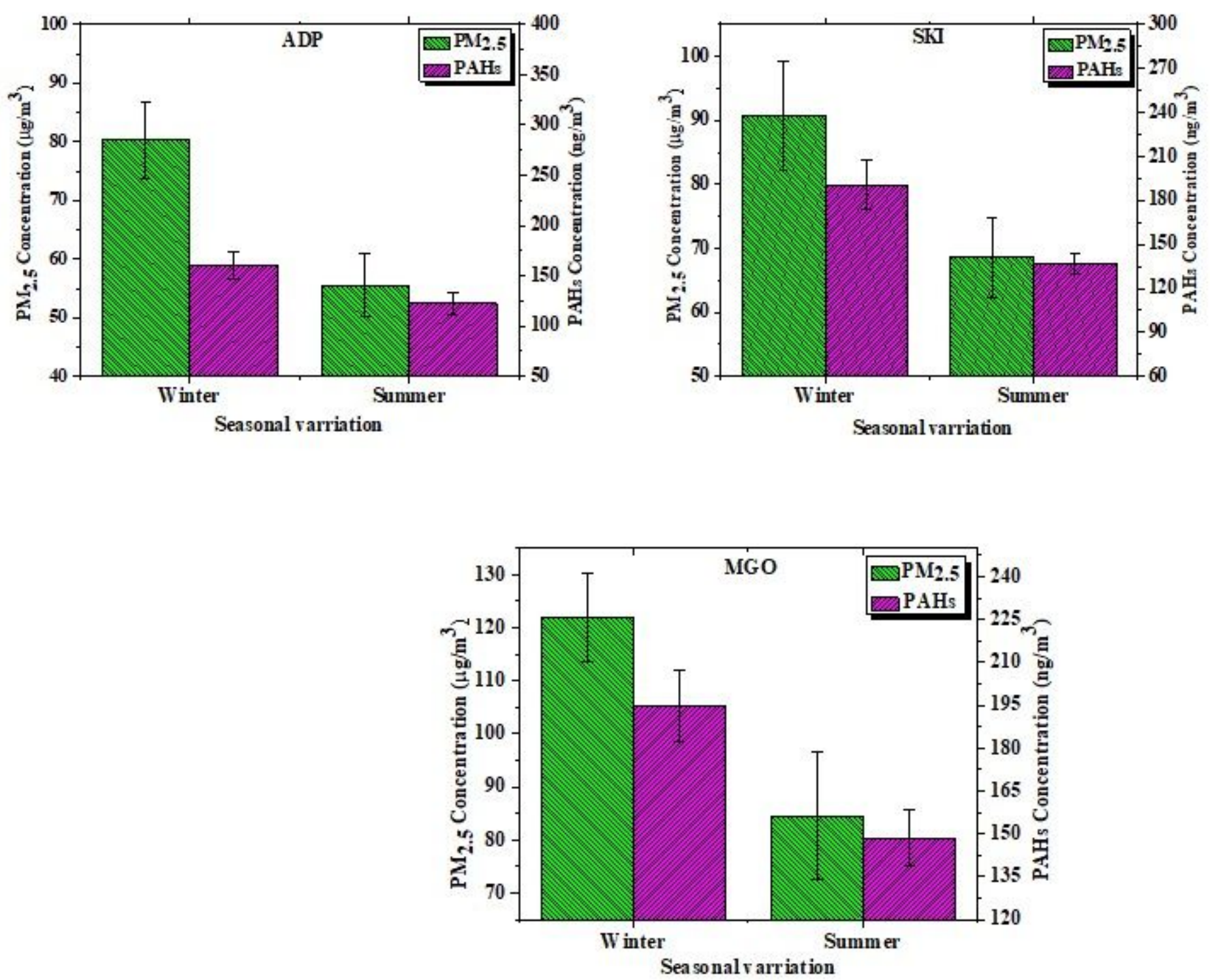

Figure 3

Seasonal concentration of PM2.5 $(\mu \mathrm{g} / \mathrm{m} 3)$ and PAHs $(\mathrm{ng} / \mathrm{m} 3)$ over three CNP traffic sites. 

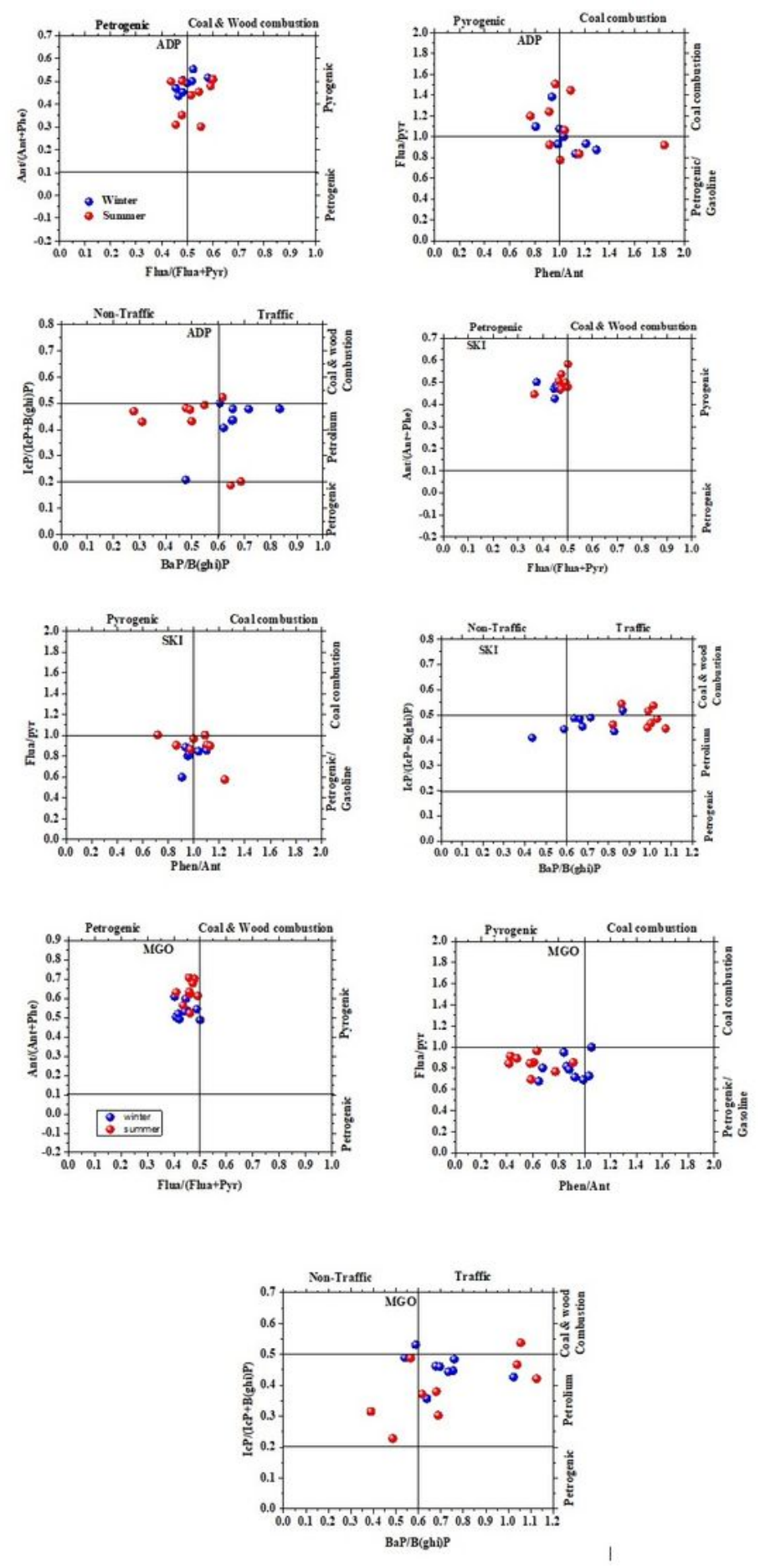

\section{Figure 4}

Diagnostic Ratio analysis for source apportionment over three sites ADP, SKI \& MGO of CNP. 

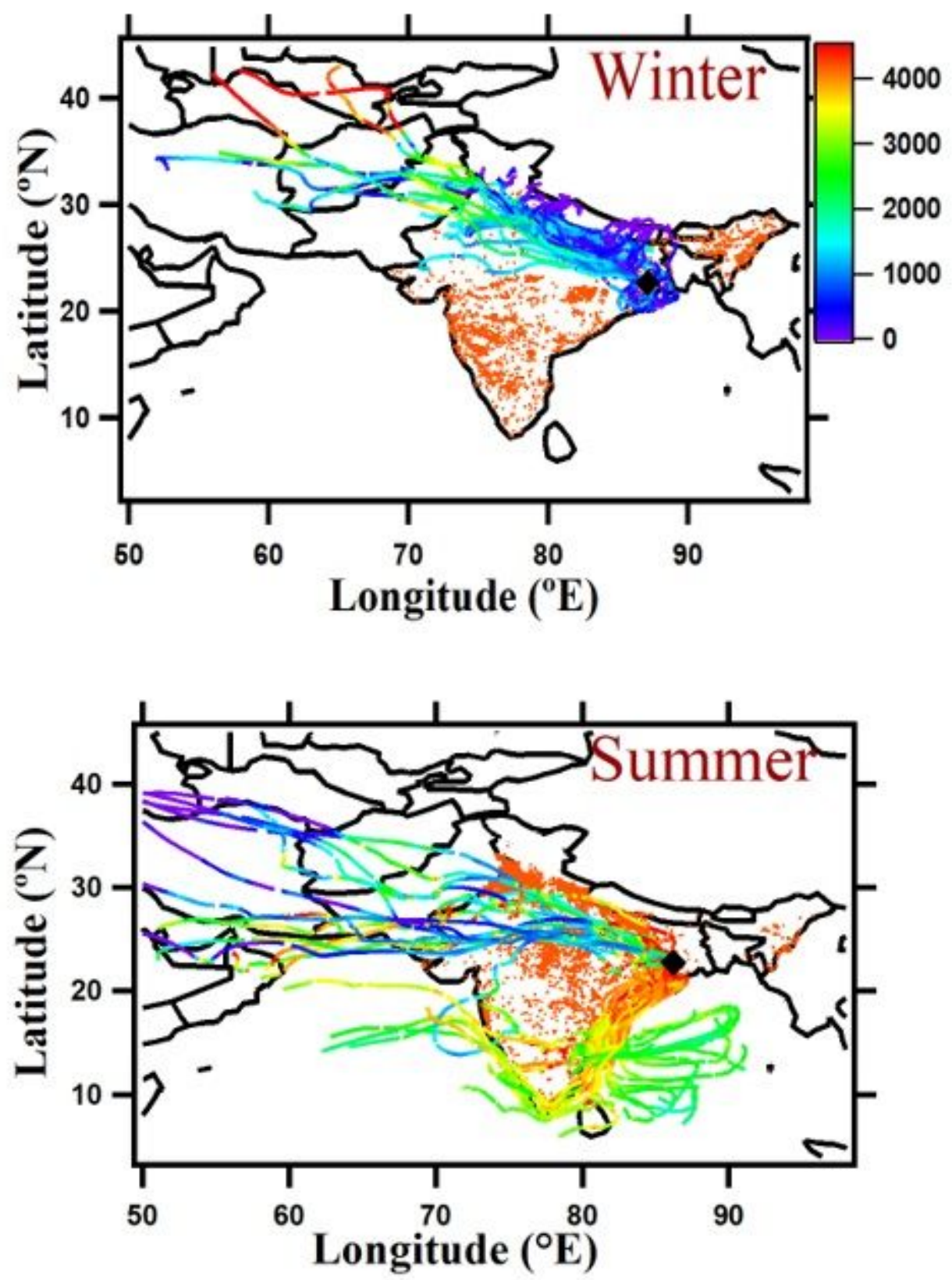

Figure 5

7 Days Backward trajectories up to $500 \mathrm{~m}$ from the surface and fire count data of East India (Lattitude22.80460N, Longitude- 86.2029 OE)

\section{Supplementary Files}

This is a list of supplementary files associated with this preprint. Click to download.

- Table.pdf 